\title{
Laparoscopic Repair of Non-midline Abdominal Wall Hernia: Retrospective Analysis of Cases done by a Single Surgeon in the Past Four Years
}

\author{
1Jitendra Kumar, ${ }^{2}$ Rajni Raina
}

\begin{abstract}
Aim: Abdominal wall ventral hernias are either midline or nonmidline. Non-midline abdominal wall hernias are not a common entity and even rarer is a lateral ventral hernia. Laparoscopic management of these hernias are surgically challenging, and outcomes are unpredictable. This study aims to evaluate and analyze the results of laparoscopic repair of comparatively rare non-midline hernias done at the tertiary teaching hospital in the span of last four years.
\end{abstract}

Material and methods: For this retrospective descriptive study, from record file, all cases of laparoscopic ventral hernia repair done in the last four years (from 01/01/2012 to 01/01/2016) by the main author at Lady Hardinge Medical College screened and out of these, total of thirteen cases (n-13) of non-midline ventral hernia selected for their data analysis.

Results: Out of total thirteen cases $(n=13)$, a large percentage was of female gender (76.92\%), their mean age of the patients were $43+/-9.30$ years. $(S D=11.41)$. Range $24-64$ years. Most of the patients were overweight with mean weight was $72.846 \mathrm{~kg}$. $(S D=13.369)$. Mean operating time were 78.84 minutes $(S D=22.62)$ (range $60-120$ minutes). One patient (7.69\%) had developed chronic infected discharging sinus which ultimately required removal of mesh. Same and only patient in our series reported recurrence which makes an overall percentage of recurrence $07.69 \%$.

Conclusion: Even though non-midline abdominal wall hernias are comparatively atypical in its presentation and challenging for the laparoscopic surgeon, overall patient's epidemiology, the surgical outcome in term of recurrence and complications are not much different.

Clinical significance: Presentation of a non-midline hernia is atypical and surgically complex which require an experience to handle it.

Keywords: Complex hernia, Non-midline ventral hernia, Lateral abdominal wall hernia, Non-midline incisional hernia, Laparoscopic ventral hernia repair.

How to cite this article: Kumar J, Raina R. Laparoscopic Repair of Non-midline Abdominal Wall Hernia: Retrospective

\footnotetext{
${ }^{1}$ Assistant Professor, ${ }^{2}$ Specialist

${ }^{1}$ Department of Surgery, Lady Hardinge Medical College and Smt. S. K. Hospital, New Delhi, India

${ }^{2}$ Department of Anaesthesia. Dr Baba Saheb Ambedkar Medical College and Hospital, New Delhi, India

Corresponding Author: Jitendra Kumar, Assistant Professor, Department of Surgery, Lady Hardinge Medical College and Smt. S. K. Hospital, New Delhi, India, email: jkumar33@ymail.com
}

Analysis of Cases done by a Single Surgeon in the Past Four Years. World J Lap Surg 2018;11(2):85-89.

Source of support: Nil

Conflict of interest: None

\section{INTRODUCTION}

Abdominal wall hernia represents the hernias coming out through defects in the abdominal wall fascia and muscle through which intra-abdominal or pre-peritoneal contents protrudes out. It can be either spontaneous or as a consequence of past surgery involving incision of the abdominal wall. Most of the time abdominal wall hernia tends to originate out of the midline probably through linea alba or weak midline vertical scar. ${ }^{1}$ Although abdominal wall hernias in its mid-line anatomical location whether spontaneous or incisional are very common, non-midline abdominal wall hernias are comparatively rare entity and even rarer is spontaneous lateral abdominal wall ventral hernia. ${ }^{2}$

Even though non-midline or lateral abdominal wall hernias are rare occurrences and its management and outcome is not as simple as other ventral abdominal wall hernias, available data's or literature in respect of this is very limited. Even textbooks have not dedicated any separate chapter in respect of non-midline or lateral abdominal wall hernias. ${ }^{3}$

In 1992, Leblanc first reported the repair of abdominal wall ventral hernia by laparoscopic route. He performed the surgery using four to five port and all repairs were made using 1-mm-thick expanded polytetrafluoroethylene patches inserted intraperitoneally and stapled to the anterior abdominal wall over the defects, making use of intra-abdominal pressure to secure the repair. ${ }^{4}$ Since then laparoscopic repair of ventral abdominal wall hernia has evolved rapidly and now been considered as well accepted and preferred approach for management of abdominal wall ventral hernia. ${ }^{5}$

\section{MATERIALS AND METHODS}

For this retrospective descriptive study, the record of all cases of non-midline ventral hernia repaired laparoscopically by the main author himself during the period from 
1 January 2012-1 January 2016 has been screened. Total of thirteen cases $(n=13)$ of a non-midline hernia found to be eligible for study in term of detail availability of case record. Apart from demographic and clinical profile, e.g., age, sex, weight, symptoms and its duration, comorbidity, past history of surgery; total duration of surgery (from making first incision to taking last suture), all intra and postoperative events, e.g., size and location of defect, intra and postoperative different complications, follow up period and reported recurrence looked in to and evaluated in detail.

\section{Surgical Techniques}

All cases were done as an elective case at Lady Hardinge Medical College and Smt. S.K. Hospital, New Delhi. For preoperative preparation, all patients were made medically fit in term of any associated medical comorbidities, diabetes control, cessation of smoking, weight reduction, etc. Operative techniques followed according to SAGES guideline and adhered to standard protocols based on different recommended trials. ${ }^{6-8}$ All cases were done under general anesthesia. All cases involving hernia below umbilical line had been routinely catheterized after induction of anesthesia and catheter was removed soon after completion of surgery. Strict antiseptic and aseptic protocols have been followed.

The procedure starts with the creation of pneumoperitoneum by a close technique using veres needle mostly at palmer point or infra/supra umbilical location depending on the location of a hernia. First port inserted blindly and rest of the port under camera vision. In all cases, three ports, one camera $10-11 \mathrm{~mm}$ and two working port of $5 \mathrm{~mm}$ has been used. Placement of ports depends on site of a hernia. Mostly port has been placed on the lateral side of the abdomen with camera port in the center and at the possible distant location from defect area. ${ }^{9}$ After a thorough inspection of inside the abdomen first thing we do is adhesiolysis using electrocautery or a harmonic scalpel. A lot of patience and precautions are required for this step to prevent complication like bowel injury. Then reduction of the abdominal contents from the hernia sac performed gently and carefully. We do not close the defect or approximate its margin by any means, rather we pull the redundant sac and tack this to adjoining normal abdominal wall as this helps in reducing the dead space and preventing the postoperative seroma formation.

After removal of fatty deposits around the defect and thorough hemostasis, we measure defect size to plan the placement of adequate size of mesh. As per recommendation mesh should be of a size which can overlap beyond 5 $\mathrm{cm}$. of defect margin. ${ }^{9}$ In cases where mesh had to place over the defect situated near the iliac or pubic bone in the lower part of abdomen we reflected the peritoneum after dissecting it and mesh been tacked over ligament or in some case over bone. In upper abdominal hernia defect, we dissect the falciform ligament to place the mesh in subcostal region properly. In our all cases we used composite (coated polypropylene, proceed) mesh.

During defect size measurement and fixation process of mesh, as per recommendation, we reduce the intraabdominal $\mathrm{CO}_{2}$ pressure to $5-7 \mathrm{~mm}$ of $\mathrm{Hg}$. We fixed the mesh with four quadrants trans fascial suture and circumferentially double crowning with non-absorbable titanium tack (Protack, Covidien) ${ }^{10}$ Again after being assured about hemostasis and other intra-abdominal findings, we remove the trocars under vision and suture the $10 \mathrm{~mm}$ port site with port closure needle in two-layer while rest of the port been closed with only one layer of skin closure. We usually place large cotton ball compression elastic pressure dressing over the large defect thinking to reduce postoperative seroma. Postoperatively for inspection of port site wound and hernial site, we removed the dressing of the wound after 48 hours.

\section{RESULTS}

During four years, 13 cases of nonmidline abdominal wall hernia found to be operated by the main author. Out of thirteen cases, ten $(76.92 \%)$ were female, and three $(23.07 \%)$ were male with their mean age of $43+/-9.30$ years $(S D=11.41)$. The range for age were $24-64$ years. Mean weight of the patients were $72.846 \mathrm{~kg}(\mathrm{SD}=13.369)$ in range of $52-98 \mathrm{~kg}$ (Table 1).

The average duration of hospital stay for the patients were 6.61 days $(\mathrm{SD}=4.17)$ in range of 3-19 days. Average follow-up periods were 21.15 months $(S D=11.857)$ in range of 1-40 months (Table 1 )

All patients were having a common complaint of swelling, with five patients (38.46\%) having pain along

Table 1: Epidemiological parameters and different time durations for patients

\begin{tabular}{llcc}
\hline Parameters & Range & Average/Mean & Std. deviation (SD) \\
\hline Age (in years) & $24-64$ & $43+/-9.30$ & 11.41 \\
Sex & & Female $=10(76.92 \%)$ and Male $=3(23.07 \%)$ \\
Weight (in kg.) & $52-98$ & 72.846 & 13.369 \\
Duration of symptoms (in months) & $03-108$ & 30.157 & 4.17 \\
Duration of hospital stay (in days) & $03-19$ & 6.61 & 11.857 \\
Follow-up period (in months) & $01-40$ & 21.15 & \\
\hline
\end{tabular}


with swelling, five patients were having complete reducible swelling, six $(46.15 \%)$ patients presented with partially reducible swelling and only one patient $(7.69 \%)$ presented with non-reducible swelling. Mean duration of symptoms were 30.15 months within a range of three months to hundred and eight months (Table 2).

Among all patients $(n=13)$ six patients $(46.15 \%)$ have got associated comorbidities out of which two were suffering from hypothyroidism, one hypertension along with hypothyroidism, one hypertension with dyslipidemia, one diabetes mellitus type-II and another one having hypertension. Rest of the patients (53.84\%) were not having any associated comorbidities.

Out of total 13,8 patients $(61.53 \%)$ have got history of past surgery among which $5(38.46 \%)$ were having lower abdominal surgery [LSCS-2 (15.38\%)], LSCS with open appendicectomy-1 $(07.69 \%)$, open appendicectomy-1 $(7.69 \%)$, lap. Oophorectomy $-1(07.69 \%)$ and three $(23.07 \%)$ had history of upper abdominal surgery (lap. cholecystectomy-1 (07.69\%), small open epigastric hernia repair-1 $(07.69 \%)$, exploratory laparotomy for appendicular perforation peritonitis-1 $(07.69 \%)$. Five $(38.46 \%)$ patients were not having any history of surgical intervention in the past.

Among all operated cases, anatomical location of a hernia in five cases $(38.46 \%)$ were at lower part of abdomen (right lower hypogastrium and right iliac fossa-3 $(23.07 \%)$, left lower-2(15.38\%), another five $(38.46 \%)$ found to be on upper part of abdomen (right subcostal and subxiphoid-1(07.69\%), right upper abdomen-39 $(23.07 \%)$, left upper abdomen-1 (07.69\%) and three $(23.07 \%)$ were on the line of umbilicus-left side-2 $(15.38 \%)$, right side-1 $(07.69 \%)$. All the larger size hernias were on the right lower abdomen. Out of thirteen patients, five $(38.46 \%)$ were having tender swelling on physical examination.

As expected in non-midline or lateral hernias, size of defects was of comparatively smaller diameter. Average size of defect was $06.661 \mathrm{~cm}^{2}$ (range of $2.5 \mathrm{~cm}^{2}-35 \mathrm{~cm}^{2}$ ). The largest defect found in a patient with a large hernia involving right subcostal and lumbar area. Intra-operatively, out of total thirteen patients two patient has finding

Table 2: Important clinical feature

\begin{tabular}{ll}
\hline Signs and Symptoms & Percentage \\
\hline 1. Swelling & \\
Reducible & 38.46 \\
Partially reducible & 46.15 \\
Non-reducible & 07.69 \\
2. Pain & 38.46 \\
3. Anatomical location & 38.40 \\
Above the line of umbilicus & 38.40 \\
Around the line of umbilicus & 23.07 \\
Below the line of umbilicus &
\end{tabular}

of another defect which was far laterally placed than original defect. One patient with a hernia at right hypogastrium had got defect at right iliac fossa and another patient with a hernia at right lower abdomen got defect of size $0.5 \times 0.5 \mathrm{~cm}$ at the lateral border of rectus near the semilunar line which could be a Spigelian hernia. The average size of mesh used was of diameter of $140 \mathrm{~cm} .{ }^{2}$ in range of $120 \mathrm{~cm}^{2}-225 \mathrm{~cm}^{2}$ Mean duration of operating time were 78.84 minutes $(\mathrm{SD}=22.62)$ in range of 60 to 120 minutes (Table 1).

Out of total thirteen patients, five (38.40\%) complained mild to moderate pain while two $(15.35 \%)$ had severe and prolonged pain postoperatively. One patient $(7.69 \%)$ developed acute retention of urine in the immediate post-operative period. Four patients $(30.76 \%)$ developed mild to moderate seroma, and one $(7.69 \%)$ developed hematoma at hernia site postoperatively. All of these resolved spontaneously within three months follow up period. Two patients $(15.38 \%$ ) has got cellulitis around 10 $\mathrm{mm}$ port site with the consequent discharge of pus. Out of these two patients, one ( $7.69 \%$ ) had developed chronic infected discharging sinus which ultimately required re-surgery and removal of mesh. Probably this was the reason, recurrence of a hernia happened in this patient only (Table 3).

\section{DISCUSSIONS}

Finding of only thirteen cases of non-midline ventral abdominal wall hernia during four years at tertiary care teaching institute itself suggests that it is not a common type of a hernia. Maybe this is the reason availability of studies or reports in respect of a non-midline hernia is very sparse and whatever literature available is of a limited number of series and sporadic case report. ${ }^{1-3}$ Shortage of literature is not only limited to research

Table 3: Operative details including complications

\begin{tabular}{ll}
\hline Parameters & $\begin{array}{l}\text { Average / Range / \% of total } \\
\text { patients }\end{array}$ \\
\hline $\begin{array}{l}\text { Operative time (in minutes) } \\
\text { Defect size }\end{array}$ & $\begin{array}{l}78.4(60-120) \text { S.D. }=22.62 \\
\text { - Diameter }\end{array}$ \\
- (vertical x horizontal) & $\begin{array}{l}\text { Smallest }(0.5 \times 0.5) \mathrm{cm} . \\
\text { Largest }(7 \times 5) \mathrm{cm} .\end{array}$ \\
$\begin{array}{l}\text { Complications } \\
\text { 1. Mild to moderate pain }\end{array}$ & $38.40 \%$ \\
2. Severe and prolonged & $15.35 \%$ \\
pain & \\
3. Acute retention of urine & $07.69 \%$ \\
4. Seroma & $30.76 \%$ \\
5. Hematoma & $07.69 \%$ \\
6. Cellulitis & $15.38 \%$ \\
7. Discharge & $15.38 \%$ \\
8. Required mesh removal & $07.69 \%$ \\
9. Recurrence & $07.69 \%$ \\
\hline
\end{tabular}


articles but, even textbooks are also missing any chapter or topics on this subject.

Therefore because of very little availability of report in respect of a non-midline hernia we tried to compare our results and other outcomes with studies reported in term of laparoscopic ventral hernia in general also. However, all the available reports unanimously considered nonmidline or lateral hernias as a more complex variety of abdominal wall hernia in term of its repair as well as unpredictable surgical outcome. ${ }^{11}$

In our series, we have got a common epidemiological trend of the patient's parameter as compared to other reported series of cases of laparoscopic ventral hernia repair. ${ }^{11,12}$ Most of the patients were overweight which supports the literature explaining its relation with a spontaneous ventral hernia. Comparatively this cohort has got larger share of patients with the comorbid condition which again corroborating with past studies reported comorbid condition as a frequent association with abdominal wall hernia. ${ }^{12}$

In our series, we got more percentage of painful or tender swelling as a clinical presentation in comparison to a series of another laparoscopically repaired midline ventral hernia repair. Average hospital stay for all patients of this series was also comparatively longer and was maximum for the patient who reported recurrence. Moreno-Egea et al. reported in their study titled Midline versus non-midline laparoscopic incisional hernioplasty: a comparative study, published in journal Surg Endosc. In March 2008 that non-midline hernias are associated with more preoperative pain, require more analgesics and required a more extended hospital stay than the midline incisional hernias..$^{13}$ The only explanation to this is comparatively narrow neck and sideway protrusion of sac with the more applicable constricting force of lateral abdominal wall musculature. Although it needs to be verified with further studies.

In our studies, anatomical location of a hernia was equally on upper and lower half while whatever little available studies found a location of non-midline hernias are little more common in the lower half of the abdomen. ${ }^{3}$ However, in our series average size of the lower abdominal wall located hernia were much larger and at the lateral edge of the rectus muscle. Although, right now it will be too early to comment on that.

Another important finding was the presence of another unsuspected defect far lateral to an original defect in two patients $(15.38 \%)$ of this series. It justifies the reports of many studies which has supported the laparoscopic repair of ventral hernia repair, that can cover these sort of unsuspected defect also and prevent recurrence, ${ }^{5,10}$

Average time taken for surgery in our series were 78.4 minutes which was little more than average opera- tive time reported by another series. ${ }^{14,15}$ It may be due to the complexity of a non-midline hernia and individual surgeon experience. Different postoperative complications in our series seem to be of the little higher side it may be due to small sample size and complexity of nonmidline hernia. ${ }^{13,15,16 .}$

One patient was required for removal of his mesh due to infection and not responding to other conservative management. Same and only patient in our series reported recurrence which overall percentage would be $07.69 \%$. In most of the series recurrence rate reported are between about four to seven percent which is quite comparable to our result. ${ }^{14-17}$.

Most of the reported studies found a reduction in the duration of operating time and surgical complications with an increase in the experience of a surgeon. The same thing is true here with author's finding, as apart from a reduction of the time duration of surgery with experience, one patient with a spontaneous right subcostal hernia which has got recurrence was a first patient of this series of non-midline ventral hernia. ${ }^{17}$

\section{CONCLUSION}

Even though non-midline abdominal wall hernias are comparatively uncommon and surgically challenging, overall their epidemiological profile, presentation, complications, and recurrences are not much different than those of midline ventral hernias.

\section{CLINICAL SIGNIFICANCE}

Non-midline abdominal wall hernia even at its early stage presents in more symptomatic manner, and because of its rarity and complexity an experienced surgeon must supervise the beginners.

\section{ACKNOWLEDGMENTS}

Authors would like to convey their heartiest thankfulness and gratitude to Mrs Bobby and MRO Mr. Yogesh of LHMC for their huge support and cooperation in collecting the data of the patients.

\section{REFFERENCES}

1. McGlannan A. Lateral Ventral Hernia. Ann Surg. 1927 Feb;85(2):284-7. PubMed PMID: 17865625; PubMed Central PMCID: PMC1399272.

2. Holloway JK. Spontaneous Lateral Ventral Hernia. Ann Surg. 1922 Jun;75(6):677-85. PubMed PMID: 17864645; PubMed Central PMCID: PMC1400017.

3. Moreno-Egea A, Guzman P, Morales G, Carrillo A, Aguayo JL. Treatment of non-midline ventral hernia: experience in an abdominal wall unit and literature review. Cirugia espanola. 2007 Jun;81(6):330-334. 
4. LeBlanc KA, Booth WV. Laparoscopic repair of incisional abdominal hernias using expanded polytetrafluoroethylene: preliminary findings. Surg Laparosc Endosc. 1993 Feb;3(1):39-41.

5. Zhang, Y., Zhou, H., Chai, Y. et al. World J Surg. 2014 April 29; 38: 2233.

6. Bittner R, Bingener-Casey J, Dietz U, Fabian M, Ferzli GS, Fortelny RH, et al. Guidelines for laparoscopic treatment of ventral and incisional abdominal wall hernias (International Endohernia Society (IEHS) —Part 1. Surgical endoscopy. 2014 Jan 1;28(1):2-9.

7. Bittner R, Bingener-Casey J, Dietz U, Fabian M, Ferzli GS, Fortelny $\mathrm{RH}$, et al. Guidelines for laparoscopic treatment of ventral and incisional abdominal wall hernias (International Endohernia Society [IEHS])_Part 2. Surgical endoscopy. 2014 Feb 1;28(2):353-379.

8. Misiakos EP, Patapis P, Zavras N, Tzanetis P, Machairas A. Current trends in laparoscopic ventral hernia repair. JSLS: Journal of the Society of Laparoendoscopic Surgeons. 2015 Jul;19(3).

9. Alexander AM, Scott DJ. Laparoscopic ventral hernia repair. Surg Clin North Am. 2013;93:1091-1110.

10. Misiakos EP, Machairas A, Patapis P, Liakakos T. Laparoscopic ventral hernia repair: pros and cons compared with open hernia repair. JSLS: Journal of the Society of Laparoendoscopic Surgeons. 2008 Apr;12(2):117-125.
11. Lal R, Sharma D, Hazrah P, Kumar P, Borgharia S, Agarwal A. Laparoscopic management of nonmidline ventral hernia. Journal of Laparoendoscopic \& Advanced Surgical Techniques. 2014 Jul 1;24(7):445-450.

12. Park AE, JS Roth, Kavic SM. Abdominal wall hernia. Curr Probl Surg. 2006 43:32675. Medline

13. Moreno-Egea A, Carrillo A, Aguayo JL. Midline versus nonmidline laparoscopic incisional hernioplasty: a comparative study. Surgical endoscopy. 2008 Mar 1;22(3):744-749.

14. Heniford BT, Park A, Ramshaw BJ, Voeller G. Laparoscopic repair of ventral hernias: nine years' experience with 850 consecutive hernias. Ann Surg. 2003 Sep;238(3):391-399; discussion 399-400. PubMed PMID: 14501505; PubMed Central PMCID: PMC1422707.

15. Goodney PP, Birkmeyer CM, Birkmeyer JD. Short-term outcomes of laparoscopic and open ventral hernia repair. Arch Surg. 2002; 137:1161-5.

16. Ferrari GC, Miranda A, Sansonna F, Magistro C, Di Lernia S, Maggioni D, Franzetti M, Costanzi A, Pugliese R. Laparoscopic repair of incisional hernias located on the abdominal borders: a retrospective critical review. Surgical Laparoscopy Endoscopy and Percutaneous Techniques. 2009 Aug 1;19(4):348-352.

17 LeBlanc KA, Whitaker JM, Bellanger DE, Rhynes VK. Laparoscopic incisional and ventral hernioplasty: lessons learned from 200 patients. Hernia. 2003 Sep;7(3):118-124. Epub 2003 Mar 21. PubMed PMID: 12942345. 